\title{
A comparison of satellite hyperspectral and multispectral remote sensing imagery for improved classification and mapping of vegetation
}

\author{
M Govender ${ }^{1}, K_{\text {Chetty }}^{2}$, V Naiken ${ }^{1}$ and H Bulcock ${ }^{2}$ \\ ${ }^{1}$ CSIR Natural Resources and the Environment, \% School of Environmental Sciences, University of KwaZulu-Natal, \\ Private Bag X01, Scottsville 3209, South Africa \\ ${ }^{2}$ School of Bioresources Engineering and Environmental Hydrology, University of KwaZulu-Natal, Private Bag X01, \\ Scottsville 3209, South Africa
}

\begin{abstract}
In recent years the use of remote sensing imagery to classify and map vegetation over different spatial scales has gained wide acceptance in the research community. Many national and regional datasets have been derived using remote sensing data. However, much of this research was undertaken using multispectral remote sensing datasets. With advances in remote sensing technologies, the use of hyperspectral sensors which produce data at a higher spectral resolution is being investigated. The aim of this study was to compare the classification of selected vegetation types using both hyperspectral and multispectral satellite remote sensing data. Several statistical classifiers including maximum likelihood, minimum distance, mahalanobis distance, spectral angular mapper and parallelepiped methods of classification were used. Classification using mahalanobis distance and maximum likelihood methods with an optimal set of hyperspectral and multispectral bands produced overall accuracies greater than $80 \%$.
\end{abstract}

Keywords: hyperspectral, multispectral, satellite data, statistical classifiers, vegetation classification

\section{Introduction}

Remotely sensed data are commonly used for the classification and mapping of vegetation over large spatial scales, replacing traditional classification methods, which require expensive and time-intensive field surveys. Since the early 1960 s, multispectral airborne and satellite remote sensing technologies have been used as a common source for the remote classification of vegetation (Landgrebe, 1999). Multispectral remote sensing technologies, in a single observation, collect data from three to six spectral bands from the visible and near-infrared region of the electromagnetic spectrum. This crude spectral categorization of the reflected and emitted energy from the earth is the primary limiting factor of multispectral sensors. Over the past 2 decades, the development of airborne and satellite hyperspectral sensor technologies has overcome the limitations of multispectral sensors. Govender et al. (2007) have reviewed the application of hyperspectral imagery in the classification and mapping of land use and vegetation and, in particular, in water resource studies.

Hyperspectral sensors collect several, narrow spectral bands from the visible, near-infrared, mid-infrared, and short-wave infrared portions of the electromagnetic spectrum. These sensors typically collect 200 or more spectral bands, enabling the construction of an almost continuous spectral reflectance signature. Furthermore, narrow bandwidths characteristic of hyperspectral data permit an in-depth examination of earth surface features which would otherwise be 'lost' within the relatively

\footnotetext{
* To whom all correspondence should be addressed.

苗 +27 33 260-5276; fax: +27 33 260-5446;

e-mail: MGovender@,csir.co.za

Received 27 November 2007; accepted in revised form 15 February 2008
}

coarse bandwidths acquired with multispectral data.

Hyperspectral data at a finer spectral resolution can be used to improve vegetation classification, by detecting biochemical and structural differences in vegetation (Yamano et al., 2003; Underwood et al., 2003; Galvao et al., 2005; Koch et al., 2005). Research is underway to determine if data of a higher spectral resolution could be used to discriminate vegetation at individual genus and species level.

The aim of this study was to compare the classification of selected vegetation classes using both hyperspectral and multispectral satellite remote sensing data. The two data sources selected included the Proba CHRIS (Compact High Resolution Imaging Spectrometer) multispectral sensor and Hyperion hyperspectral sensor. Supervised classification was undertaken using the statistical classifiers, maximum likelihood, minimum distance, mahalanobis distance, spectral angular mapper and parallelepiped methods.

\section{Methods}

\section{Description of study area}

The Mistley-Canema Estate is situated in the Sevenoaks district approximately $70 \mathrm{~km}$ from Pietermaritzburg in the KwaZuluNatal midlands (Fig. 1).

The bio-resource group of the study area is the moist midlands mist-belt (Camp, 1997). The climate is humid, with annual rainfall ranging from $800 \mathrm{~nm}$ to $1280 \mathrm{~mm}$ and a mean annual temperature of $17^{\circ} \mathrm{C}$. The natural vegetation of the area was previously Themeda triandra grassland. Only a few relic patches remain. The soils are highly leached and forestry and sugarcane is considered ecologically suitable and are the most widespread vegetation classes on this estate (Everson et al., 2006). Vegeta- 


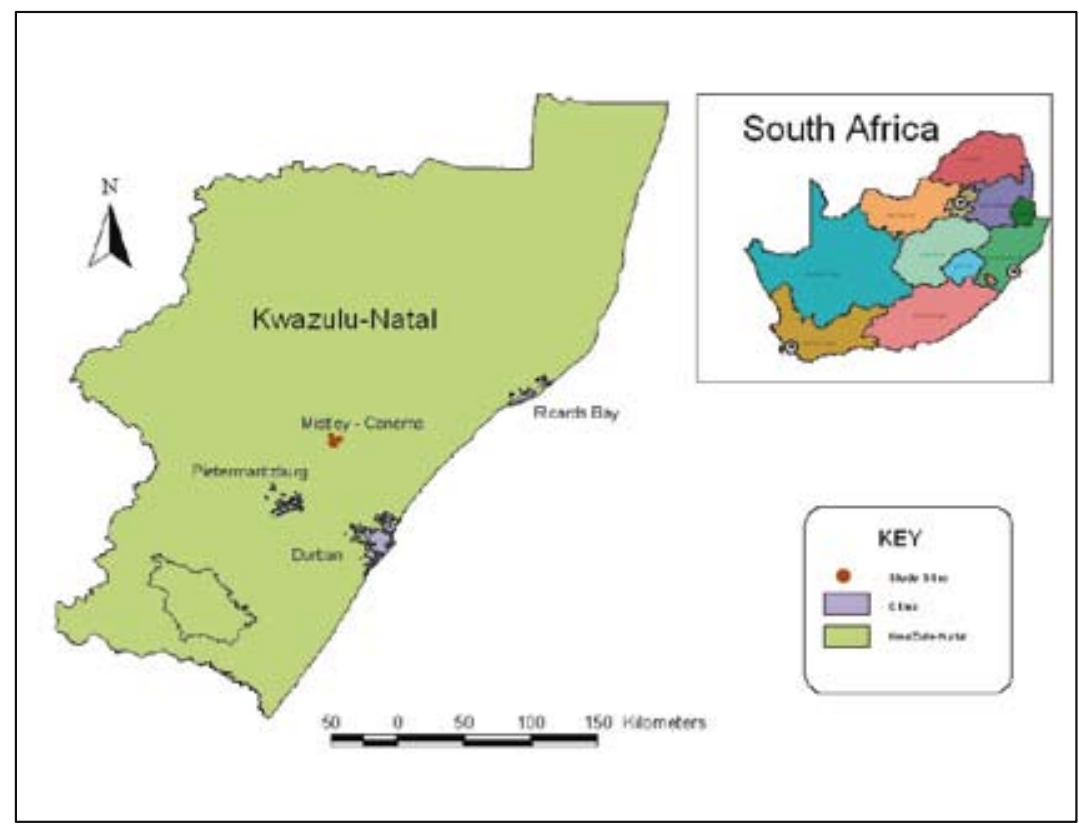

Figure 1

Location of the Mistley-

Canema study site

tion classes selected for this study were Acacia mearnsii, Pinus patula, Eucalyptus macarthurii, Eucalyptus grandis and Saccharum.

Thirteen different soil types were identified within the study area with the Inanda soil formation being dominant and on which a majority of the vegetation classes of interest are located. Some of the E. grandis sites are located on the Hutton soil form and P. patula and E. macarthurri are found on Glenrosa and Nomanci soils respectively.

\section{Selection of satellite hyperspectral data sources}

The spectral, spatial and temporal resolution, as well as the cost and availability of data, were considered when reviewing the most appropriate data source(s) for this research. The Hyperion hyperspectral sensor (United States Geological Survey Earth Resources Observation Systems) and the multispectral Proba CHRIS sensor (European Space Agency) were then selected for use in this study. A Hyperion image is a $42 \mathrm{~km}$ by $7.7 \mathrm{~km}$ scene displaying a $30 \mathrm{~m}$ spatial resolution, comprising 242 spectral bands ranging from $357 \mathrm{~nm}$ to $2576 \mathrm{~nm}$. A CHRIS image is a 13 $\mathrm{km}$ by $13 \mathrm{~km}$ scene, at a spatial resolution of $17 \mathrm{~m}$, comprising 18 spectral bands ranging from $485.6 \mathrm{~nm}$ to $796.1 \mathrm{~nm}$.

\section{Data collection}

Remote sensing data were acquired over the Mistley-Canema site, with concurrent ground measurements of leaf spectral reflectance required for the calibration and classification of vegetation. Ancillary data collected included geographic coordinates and ground control points, aspect, soils information and biophysical descriptions of each forestry compartment. The spectral characteristics of vegetation differ from season to season. Therefore data were collected during the winter (July 2006) and summer (February 2007) to account for plant physiological differences over the dry and wet seasons and enhanced spectral differences.

\section{Satellite remote sensing data}

During winter 2006, both Hyperion and Proba CHRIS imagery was acquired. The Hyperion image was acquired on 12 July 2006, with less than $25 \%$ cloud cover. Two Proba CHRIS images were acquired on 20 and 22 July 2006 using pre-selected spectral bands, which are commonly used when vegetation studies at high spatial resolutions are intended. To complement the spatial data collected during the winter season, two earth observation datasets, Hyperion and Proba CHRIS were planned for the summer field campaign. However, all three of the Hyperion images acquired in January and February 2007 contained a high percentage of cloud cover (greater than 20\%) and therefore could not be utilised in the project. Proba CHRIS images were obtained on 13 February 2007 for the summer campaign allowing for seasonal comparisons using the Proba CHRIS datasets only.

\section{Ground-truthing surveys}

Ground-truthing surveys should be undertaken within 15 days of acquiring satellite remote sensing imagery (Ahmed, 2006). The winter and summer field campaigns took place on 12, 25 and 26 July 2006 and on 6, 7 and 8 February 2007, respectively. The sampling method undertaken involved identifying each tree species, their respective age classes and location within the forestry compartments. The compartments selected for sampling during the winter field campaign included two Saccharum sites (4 years old); two A. mearnsii sites (6 years old); , three P. patula sites of 12,15 , and 16 years old; ; two E. macarthurii sites (10 and 12 years old) and an 8-year-old E. grandis site. The same sampling sites were used in the summer field campaign with the exception of the 16- year-old P. patula which was felled prior to the summer field campaign. A random sampling method was used across the compartments, with 10 samples selected in each compartment. In addition calibration sites were selected within the study area for use in atmospheric correction. The ASD handheld spectrometer was used to obtain quantitative measurements of radiant energy easily and efficiently.

\section{Pre-processing of remote sensing data}

\section{Geometric and atmospheric correction}

Images were geometrically corrected using ground control points collected during the winter field campaign and a geo- 
rectified spatial coverage of the forestry compartments located in the catchment. All images were projected to UTM 36S, datum WGS 84.

Interference effects of the atmosphere had resulted in significant noise levels in both datasets. The empirical line method was utilized to atmospherically correct both the Hyperion and Proba CHRIS datasets. This method compares radiance values coming back from the surface to reflectance values measured on the ground with a calibrated hand-held spectrometer (Research Systems Inc, 2005). The calibration sites which were collected using the ASD spectrometer during the winter field campaign were used to convert radiance into reflectance data.

\section{Data reduction}

Data-reduction methods are used to manipulate high spectral resolution datasets, to reduce high data dimensionality and the complexity which arise when applying statistical classifiers to such datasets. Furthermore, by reducing data dimensionality an optimal set of spectral bands which best characterise a specific vegetation class can be identified. Two data-reduction methods were applied to the hyperspectral and multispectral datasets. These included the analysis of variance and minimum noise fraction with maximum band selection.

The data-reduction procedures as outlined by Ismail et al. (2007 were adopted as the first method to obtain an optimal set of spectral bands for both remote sensing datasets. In this method it was assumed that a distinct collection of spectral bands can be used to discriminate between genus/species. Thirty spectral sample points per genus/species were used to determine the significant differences between spectral wavelengths using a oneway analysis of variance (95\% confidence limit) with Tukey's post hoc test for 21 class pairs. Frequency distributions were then plotted, using the total number of significant bands at each spectral wavelength for all the classes and were used to discriminate spectrally between classes. The frequency analysis highlighted significant regions of the electromagnetic spectrum for both the Proba CHRIS and Hyperion imagery viz. NIR region (700 $\mathrm{nm}$ to $900 \mathrm{~nm})$ and IR and SWIR region (900 nm to $1400 \mathrm{~nm}$ ) respectively. The Jeffries-Matusita separability index was not utilized to test for band separability as the analysis of variance methodology sufficiently reduced the data dimensionality of both the hyperspectral and multispectral datasets (Richards and Jia, 1999; Vaiphasa et al., 2005; Ismail et al., 2007). The most significant spectral bands with the highest frequencies were selected for each individual class. The Hyperion hyperspectral dataset reduced significantly from 242 to 27 spectral bands (referred to as Hyperion reduced Set A), ranging from $900 \mathrm{~nm}$ to $1400 \mathrm{~nm}$, while the Proba CHRIS multispectral data reduced from 18 to 9 spectral bands, ranging from $450 \mathrm{~nm}$ to $550 \mathrm{~nm}$ and $700 \mathrm{~nm}$ to $800 \mathrm{~nm}$.

The second method applied only to the hyperspectral data, used minimum noise fraction to segregate noise in the datasets, identify and remove these 'noisy bands' and to reduce the computational requirements for analyses as adopted by (Green et al., 1988; Lee et al., 1990). In addition to removing the "noisy bands' from the Hyperion dataset, an optimal subset of bands was determined using known regions of interest for vegetation classes (targets) and background materials in the image. The optimal spectral subset included a reduced dataset in which 'noise' had been removed and which best characterized the vegetation classes selected for this study. This approach increased the accuracy of the classification process. The Hyperion hyperspectral dataset reduced significantly from 242 to 23 spectral bands (referred to as Hyperion reduced Set B), ranging from 793 $\mathrm{nm}$ to $2375 \mathrm{~nm}$.

\section{Procedures for classification}

Regions of interest were selected for the training and validation phases performed during supervised classification. Regions of interest may be defined within the context of remote sensing as areas of an image which contain pixels of the same spectral characteristics which represent the same vegetation type.

Regions of interest were selected using ground control points and compartment boundary overlays of the MistleyCanema Estate, which were verified during field surveys. These regions were selected to represent 8-year-old E. grandis, 10and 12-year-old E. macarthurri, 12- and 16-year-old P. patula, 4-year- old Saccharum and 6-year-old A. mearnsii.

Two statistical measures were used to assess the spectral separability of the selected regions of interest: the Jeffries-Matusita and transformed divergence separability measures (Richards and Jia, 1999). All regions of interest when analysed produced a high spectral separability.

A review of several studies on vegetation classification indicates that different statistical classifiers perform well with different vegetation types and using different remote sensing data sources (Kruce et al., 1993; Lillesand and Kiefer, 1999; Castro-Esau, 2004; South et al., 2004; Belluco et al., 2006). Due to this variability, five commonly used statistical classifying techniques were used in the training phase of the classification process. These techniques included maximum likelihood, minimum distance, mahalanobis distance, spectral angular mapper and parallelepiped. An iterative process was followed to determine the optimized parameters required for each statistical classifier. Thomlinson et al. (1999) suggested an overall accuracy of greater than $85 \%$ as indicator of superior classification. However, in this study only those statistical classifying techniques with an overall accuracy of greater than $80 \%$ during the training phase were selected for validation. Accuracy assessments were used to determine which statistical classifier produced best classification results. The kappa coefficient of agreement and the overall accuracy $(>80 \%)$ were the two statistics most prominently used for decision making purposes (Foody and Mathur, 2006). The user's accuracy was used to evaluate how well an individual vegetation class was classified for a specific statistical classifier method.

\section{Results and discussion}

\section{Training phase of classification}

Training regions were spatially subset from the Hyperion and Proba CHRIS images. Regions of interest were selected to represent 8-year-old E. grandis, 10 - and 12- year-old $E$. macarthurri, 12- and 16-year-old P. patula, 4-year-old Saccharum and 6-year-old A. mearnsii. An iterative process was followed to determine the optimized parameters required for each of the 5 statistical classifier methods. The performance of each statistical classifying method was evaluated using accuracy assessments ( $>80 \%$ overall accuracy) as shown in Table 1. The training results of 2 Hyperion reduced Datasets A (27 spectral bands) and B (23 spectral bands) are shown independently in Table 1. From the training phase, the mahalanobis distance and the maximum likelihood methods most accurately classified the vegetation classes used in this study, achieving overall accuracies above $80 \%$. For all 4 datasets, the parallelepiped method did not perform well, achieving overall accuracies ranging from $3 \%$ to $64 \%$. 


\begin{tabular}{|c|c|c|c|c|c|c|c|c|}
\hline \multicolumn{9}{|c|}{$\begin{array}{c}\text { TABLE 1 } \\
\text { Accuracy assessment: training phase }\end{array}$} \\
\hline \multirow{2}{*}{$\begin{array}{l}\text { Supervised classifi- } \\
\text { cation } \\
\text { methods }\end{array}$} & \multicolumn{2}{|c|}{$\begin{array}{c}\text { Proba CHRIS } \\
\text { (winter } 2006 \text { survey) }\end{array}$} & \multicolumn{2}{|c|}{$\begin{array}{c}\text { Proba CHRIS } \\
\text { (summer } 2007 \text { survey) }\end{array}$} & \multicolumn{2}{|c|}{$\begin{array}{l}\text { Hyperion reduced set } A \\
\text { (winter } 2006 \text { survey) }\end{array}$} & \multicolumn{2}{|c|}{$\begin{array}{l}\text { Hyperion reduced set B } \\
\text { (winter } 2006 \text { survey) }\end{array}$} \\
\hline & $\begin{array}{c}\text { Kappa } \\
\text { coefficient }\end{array}$ & $\begin{array}{c}\text { Overall } \\
\text { accuracy } \\
(\%)\end{array}$ & $\begin{array}{c}\text { Kappa } \\
\text { coefficient }\end{array}$ & $\begin{array}{c}\text { Overall } \\
\text { accuracy } \\
(\%)\end{array}$ & $\begin{array}{c}\text { Kappa } \\
\text { coefficient }\end{array}$ & $\begin{array}{c}\text { Overall } \\
\text { accuracy } \\
(\%)\end{array}$ & \begin{tabular}{c|} 
Kappa \\
coefficient
\end{tabular} & $\begin{array}{c}\text { Overall } \\
\text { accuracy } \\
(\%)\end{array}$ \\
\hline Parallelepiped & 0.55 & 63.92 & 0.56 & 62.82 & 0.14 & 28.48 & 0.03 & 3.98 \\
\hline Minimum distance & 0.88 & 90.36 & 0.58 & 65.13 & 0.38 & 46.86 & 0.53 & 59.42 \\
\hline Mahalanobis distance & 0.90 & 91.91 & 0.91 & 92.75 & 0.83 & 85.45 & 0.78 & 80.86 \\
\hline Maximum likelihood & 0.99 & 99.22 & 0.97 & 97.48 & 0.99 & 98.93 & 0.99 & 98.93 \\
\hline Spectral angle mapper & 0.75 & 75.21 & 0.76 & 77.36 & 0.59 & 64.93 & 0.39 & 48.09 \\
\hline
\end{tabular}

\begin{tabular}{|l|c|c|c|c|c|c|c|c|}
\hline \multicolumn{7}{|c|}{ Accuracy assessments: validation phase } \\
\hline $\begin{array}{l}\text { Supervised classifi- } \\
\text { cation } \\
\text { methods }\end{array}$ & \multicolumn{2}{|c|}{$\begin{array}{c}\text { Proba CHRIS } \\
\text { (winter 2006 survey) }\end{array}$} & $\begin{array}{c}\text { Proba CHRIS } \\
\text { (summer 2007 survey) }\end{array}$ & $\begin{array}{c}\text { Hyperion reduced set A } \\
\text { (winter 2006 survey) }\end{array}$ & $\begin{array}{c}\text { Hyperion reduced set B } \\
\text { (winter 2006 survey) }\end{array}$ \\
\cline { 2 - 9 } & $\begin{array}{c}\text { Kappa } \\
\text { coefficient }\end{array}$ & $\begin{array}{c}\text { Overall } \\
\text { accuracy } \\
(\%)\end{array}$ & $\begin{array}{c}\text { Kappa } \\
\text { coefficient }\end{array}$ & $\begin{array}{c}\text { Overall } \\
\text { accuracy } \\
\text { (\%) }\end{array}$ & $\begin{array}{c}\text { Kappa } \\
\text { coefficient }\end{array}$ & $\begin{array}{c}\text { Overall } \\
\text { accuracy } \\
(\%)\end{array}$ & $\begin{array}{c}\text { Kappa } \\
\text { coefficient }\end{array}$ & $\begin{array}{c}\text { Overall } \\
\text { accuracy } \\
\text { (\%) }\end{array}$ \\
\hline Mahalanobis distance & 0.83 & 85.89 & 0.90 & 91.60 & 0.88 & 89.13 & 0.78 & 80.86 \\
\hline Maximum likelihood & 0.97 & 98.80 & 1.00 & 99.86 & 0.98 & 98.68 & 0.99 & 98.93 \\
\hline
\end{tabular}

The classification of the vegetation classes using the different classifying techniques were further verified by mapping individual vegetation classes across the training area and comparing their spatial distribution to true colour images and spatial maps of forestry compartments obtained from Mondi. Figure 2 illustrates the classification and mapping of the best discriminated vegetation classes using Proba CHRIS and Hyperion remote sensing imagery. Each classification can be compared to the true colour image shown in Fig. 2a. Figures $2 b, d, f, h$ represent the mahalanobis distance classifications using Proba CHRIS images obtained during winter and summer, and the Hyperion reduced Datasets A and B acquired in winter respectively. Figures 2c, $\mathrm{e}, \mathrm{g}, \mathrm{j}$ represent the maximum likelihood classifications using Proba CHRIS images obtained during winter and summer, and the Hyperion reduced Datasets A and B acquired in winter respectively.

For the Proba CHRIS multispectral images, the mahalanobis classifier consistently classified the A. mearnsii and Saccharum satisfactorily during winter (Fig. 2b) and summer (Fig. 2d). Conversely, the maximum likelihood method only classified $A$. mearnsii adequately, for the same set of images (Figs. 2c and e). Furthermore, the maximum likelihood method satisfactorily classified the 10- and 12-year-old E. macarthurii and 12-yearold P. patula species during winter (Fig. 2c); and 12-year-old E. macarthurii during summer (Fig. 2d). Due to E. macarthurii compartments being felled prior to the summer campaign, the proportions of this species classified and mapped during winter and summer are variable.

The Hyperion hyperspectral reduced Dataset A (27 spectral bands ranging from 900 to $1400 \mathrm{~nm}$ ) best classified A. mearnsii and Saccharum using the mahalanobis distance method (Fig. 2f); and A. mearnsii and the 12-year-old P. patula using the maximum likelihood method (Fig. 2g). Similarly, A. mearnsii was satisfactorily classified when applying both statistical classifiers to the reduced Hyperion Dataset B which comprised of 23 spectral bands ranging from $793 \mathrm{~nm}$ to 2375 $\mathrm{nm}$ (Figs. $2 \mathrm{~h}$ and $\mathrm{j}$ ).
The training results imply that classification of different genera and species is affected by optimal band selection and the statistical classifier method adopted. Furthermore, discriminating between different genera and species is influenced by seasonal physiological changes in vegetation which are highlighted during the dry winter and wet summer seasons.

\section{Validation phase of classification}

The mahalanobis distance and maximum likelihood statistical classifiers were selected from results of the training phase for validation. Validation was performed using the entire study area. Accuracy assessments were used to evaluate each classification as shown in Table 2. Both methods performed well, with overall accuracies above $80 \%$. However, for all 4 datasets the maximum likelihood classifications achieved the highest overall accuracies above $98 \%$.

The classifications of each vegetation class at their respective age groups were evaluated to determine how accurately the statistical classifiers, mahalanobis distance and maximum likelihood performed at a species level. This evaluation was undertaken by comparing the user's accuracy for each for each vegetation class (Table 3), with a visual assessment of their spatial distribution.

The classifications from the validation phase were mapped across the Mistley Canema Estate. Figure 3 illustrates the best discriminated vegetation classes when applying the mahalanobis distance and maximum likelihood classifiers for the Proba CHRIS and Hyperion remote sensing imagery. These classifications can be compared to true colour images in Fig. 3a. Figures $3 \mathrm{~b}, \mathrm{~d}, \mathrm{f}, \mathrm{h}$ represent the mahalanobis distance classifications using Proba CHRIS images obtained during winter and summer, and the Hyperion reduced Datasets $\mathrm{A}$ and $\mathrm{B}$ acquired in winter respectively. Figures $3 \mathrm{c}$, e, g, i represent the maximum likelihood classifications using Proba CHRIS images obtained during winter and summer, and the Hyperion reduced Datasets $\mathrm{A}$ and $\mathrm{B}$ acquired in winter respectively. The trends identified 
Figure 2

The classification and mapping of the best discriminated vegetation classes using Proba CHRIS and Hyperion remote sensing imagery during the training phase: a) true colour image, Proba CHRIS winter classification using the b) mahalanobis distance and c) maximum likelihood classification, Proba CHRIS summer classifications using d) mahalanobis distance and e) maximum likelihood,

Hyperion reduced Set $A$ winter classification using $f$ ) mahalanobis distance and g) maximum likelihood and, Hyperion reduced set $B$ winter classification

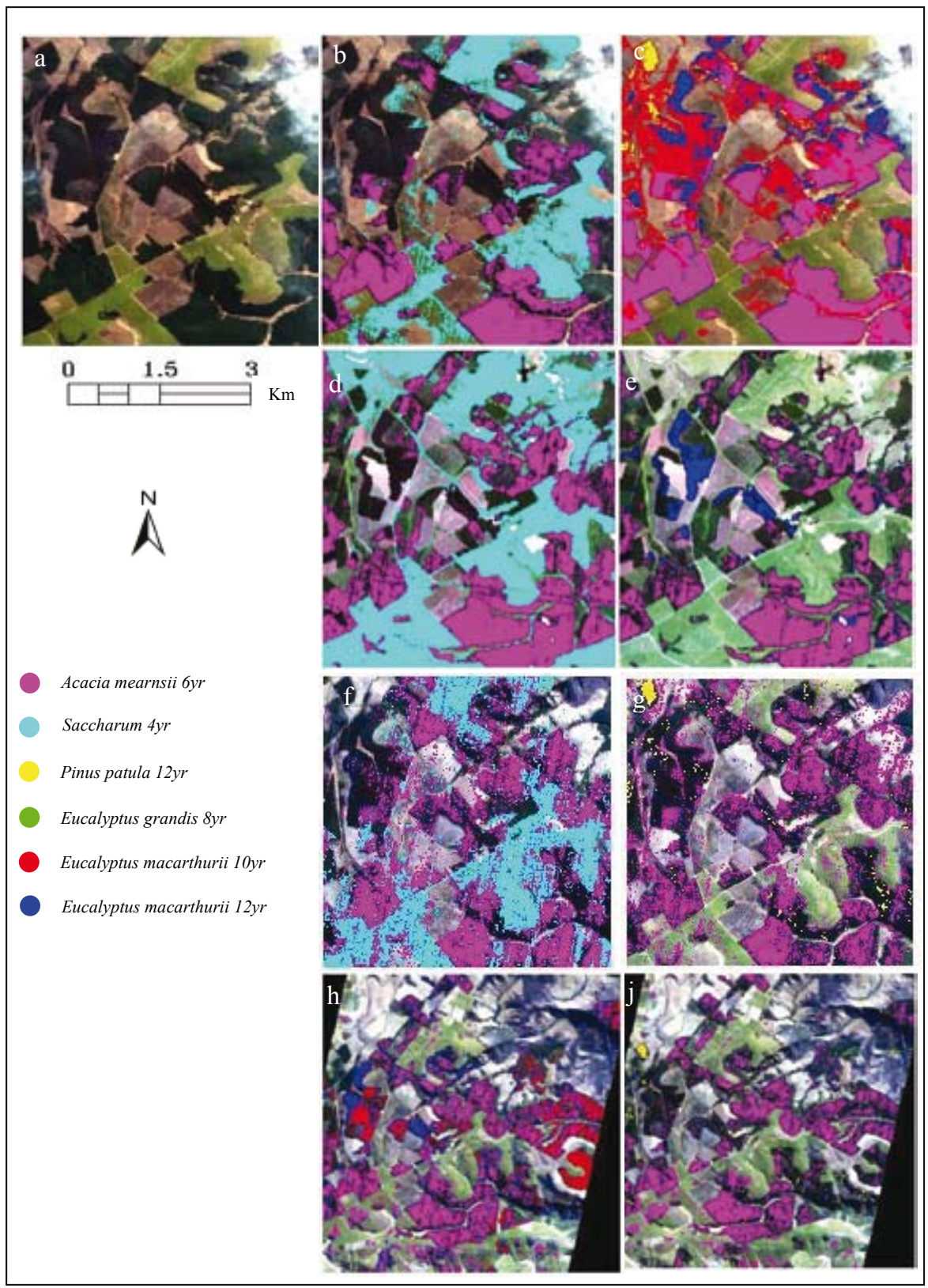

TABLE 3

User accuracy: validation phase

\begin{tabular}{|c|c|c|c|c|c|c|c|c|}
\hline \multirow[t]{2}{*}{ Vegetation classes } & \multicolumn{2}{|c|}{$\begin{array}{c}\text { User accuracy (\%) } \\
\text { Proba CHRIS } \\
\text { (winter } 2006 \text { survey) }\end{array}$} & \multicolumn{2}{|c|}{$\begin{array}{c}\text { User accuracy (\%) } \\
\text { Proba CHRIS } \\
\text { (summer 2007 } \\
\text { survey) }\end{array}$} & \multicolumn{2}{|c|}{$\begin{array}{l}\text { User accuracy (\%) } \\
\text { Hyperion reduced } \\
\text { set A (winter } 2006 \\
\text { survey) }\end{array}$} & \multicolumn{2}{|c|}{$\begin{array}{c}\text { User accuracy (\%) } \\
\text { Hyperion reduced } \\
\text { set B (winter } 2006 \\
\text { survey) }\end{array}$} \\
\hline & \begin{tabular}{|c|}
$\begin{array}{c}\text { Mahalanobis } \\
\text { distance }\end{array}$ \\
\end{tabular} & $\begin{array}{l}\text { Maximum } \\
\text { likelihood }\end{array}$ & $\begin{array}{c}\text { Maha- } \\
\text { lanobis } \\
\text { distance }\end{array}$ & \begin{tabular}{|l|} 
Maximum \\
likelihood
\end{tabular} & $\begin{array}{c}\text { Maha- } \\
\text { lanobis } \\
\text { distance }\end{array}$ & \begin{tabular}{|l|} 
Maximum \\
likelihood
\end{tabular} & $\begin{array}{c}\text { Maha- } \\
\text { lanobis } \\
\text { distance }\end{array}$ & $\begin{array}{l}\text { Maximum } \\
\text { likelihood }\end{array}$ \\
\hline $\begin{array}{l}\text { 8-year-old Eucalyptus } \\
\text { grandis }\end{array}$ & $\begin{array}{c}\text { Cloud cover } \\
\text { over site }\end{array}$ & $\begin{array}{c}\text { Cloud cover } \\
\text { over site }\end{array}$ & 100.00 & 100 & 96.39 & 100 & 77.65 & 100 \\
\hline $\begin{array}{l}\text { 10-year-old Eucalyptus } \\
\text { macarthurri }\end{array}$ & 78.40 & 100 & 76.14 & 99.04 & 76.67 & 99.07 & 80.70 & 99.08 \\
\hline $\begin{array}{l}\text { 12-year-old Eucalyptus } \\
\text { macarthurri }\end{array}$ & 76.56 & 96.24 & 68.03 & 100 & 88.64 & 97.73 & 80.46 & 96.63 \\
\hline 12-year-old Pinus patula & 78.50 & 100 & 100 & 100 & 81.05 & 100 & 75.00 & 98.81 \\
\hline 16-year-old Pinus patula & 75.00 & 100 & 100 & 100 & 76.14 & 96.91 & 75.64 & 98.95 \\
\hline 4-year-old Saccharum & 100.00 & 100 & 100 & 100 & 97.67 & 100 & 97.80 & 100 \\
\hline 6-year-old Acacia mearnsii & 100.00 & 100 & 100 & 100 & 86.02 & 98.92 & 78.57 & 98.82 \\
\hline
\end{tabular}




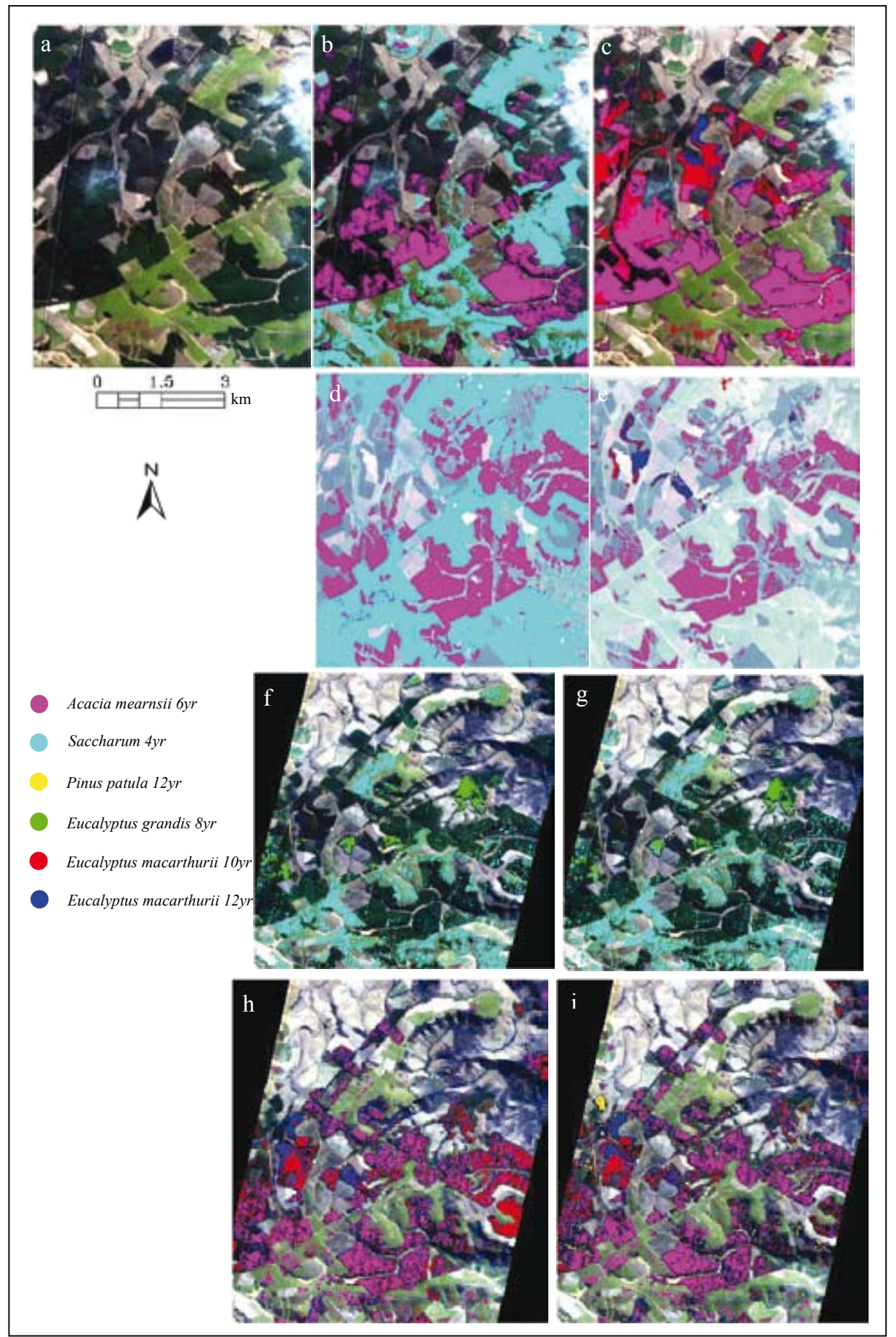

Figure 3

The classification and mapping of each vegetation class using Proba CHRIS and Hyperion remote sensing imagery during the validation phase: a) true colour image, Proba CHRIS winter classification using b) mahalanobis distance and c) maximum likelihood classification, proba CHRIS summer classifications using d) mahalanobis distance and e) maximum likelihood, Hyperion reduced set $A$ winter classification f) mahalanobis distance and g) maximum likehood and, Hyperion reduced set $B$ winter classification h) mahalanobis distance and i) maximum likehood methods.

for each dataset are discussed in the subsequent paragraphs.

During winter 2006 and summer 2007, the mahalanobis distance method best classified 4-year-old Saccharum and 6-yearold A. mearnsii using the Proba CHRIS multispectral dataset (Figs. $3 \mathrm{~b}$ and d) .In contrast, the maximum likelihood method best classified the 6-year-old $A$. mearnsii and 10- and 12-yearold E. macarthurri during winter (Fig. 3c); and 6-year-old $A$. mearnsii and 12-year-old E. macarthurri during summer (Fig. $3 \mathrm{e})$. However, the proportion of E. macarthurri classified and mapped during winter compared to summer is different (Figs. 3c and $3 \mathrm{e}$ ), as a result of selected compartments being felled prior to the summer field campaign. In general, when applying both statistical classifiers to the Proba CHRIS multispectral imagery, 6-year-old A. mearnsii is classified and mapped satisfactorily during the dry and wet season.

The results of validation phase for the Hyperion reduced Dataset A (27 spectral bands ranging from $900 \mathrm{~nm}$ to $1400 \mathrm{~nm}$ ) and B (23 spectral bands ranging from $793 \mathrm{~nm}$ to $2375 \mathrm{~nm}$ ) acquired during winter clearly demonstrate the importance of utilizing an optimal set of spectral bands to best discriminate between vegetation classes. The general both statistical classifiers best classify 4-year-old Saccharum and 8-year-old E. grandis when using the Hyperion reduced Dataset A (Figs. 3f and g). In contrast to 6-year-old $A$. mearnsii and 12-year-old $E$. macarthurri best classified using the mahalanobis distance and maximum likelihood methods with the Hyperion reduced Data- 
set B (Figs. 3h and i). Furthermore, when applying the maximum likelihood method to the Hyperion reduced Dataset B, it was possible to classify and map 12-year-old $P$. patula species as shown in Fig. $3 i$.

The validation results indicate that each remote sensing dataset with its unique combination of spectral bands have classified and mapped the individual vegetation classes to different degrees of accuracy. Variability exists within a season and between statistical classifiers across the dry and wet seasons. The validation results indicate an overall trend of genus level classification when using the Proba CHRIS multispectral bands, compared to genus and species level classification when using a unique set of Hyperion hyperspectral bands.

\section{Conclusions}

The classification and mapping of the different genera and species selected in this study were strongly affected by seasonal physiological changes in vegetation as illustrated using the multispectral Proba CHRIS remote sensing imagery, the range of spectral bands used in the classification and, the use of different statistical classifier methods. The discrimination between vegetation classes surveyed during winter and summer using the multispectral data indicate that the spectral characteristics of vegetation are significantly influenced by seasonal physiological changes in vegetation which are most prominent during the dry and wet seasons. The results from the two data-reduction methods illustrate that different combinations of spectral bands which were extracted from narrow-band hyperspectral data and the broad-band multispectral data can classify and map genera and species to different degrees of accuracy. In this study the key spectral wavelengths which best discriminate Acacia mearnsii, Pinus patula, Eucalyptus macarthurii, Eucalyptus grandis and Saccharum using the Hyperion hyperspectral data and Proba CHRIS multispectral data were identified. In general, the results from this study suggest that multispectral remote sensing data generally produced genus level classification whereas hyperspectral remote sensing data facilitated genus and species level classification. This implies that classification at a finer spectral resolution using an optimal and unique set of spectral bands is possible and can improve vegetation classification. Different statistical classifier methods and vegetation spectral reflectance indices were investigated in this project. The statistical classifiers which best classified Acacia mearnsii, Pinus patula, Eucalyptus macarthurii, Eucalyptus grandis and Saccharum during winter and summer included the mahalanobis distance and maximum likelihood methods.

It is also recommended that the developers of remote sensing technologies should utilize the findings of these types of studies in order to optimize sensor systems. Optimal hyperspectral bands which best characterize different vegetation classes should be incorporated into multispectral systems through sensor modifications or spectral filters. Using this approach researchers will no longer be restricted to existing sensor specifications, but can tailor remote sensing model inputs to a particular application. The ultimate goal is to move from impractical large data volumes and expensive sensor development towards practical operational low data volumes, high temporal resolution and cheaper sensor development.

\section{Acknowledgements}

The authors wish to thank Water Research Commission for funding this study. This work is also supported by the Euro- pean Space Agency (ESA $\left.{ }^{\circledR}\right)$ through the Tiger initiative, and acknowledgement is made for the use of Category 1Proba CHRIS data. The authors would also like to acknowledge and thank Dr Jan van Aardt and Dr Onisimo Mutanga for their comments and support in this study and the Agricultural Research Council for the use of the ASD spectrometer during the field campaigns.

\section{References}

AHMED F (2006) Personal communication. University of KwaZuluNatal, Pietermaritzburg, South Africa.

BELLUCO E, CAMUFFO M, FERRARI S, MODENESE L, SILVESTRI S, MARANI A and MARANI M (2006) Mapping salt-marsh vegetation by multispectral and hyperspectral remote sensing. Remote Sens. Environ. 105 54-67.

CAMP KGT (1997) The Bioresources Groups of KwaZulu-Natal. Cedara Report N/A/97/6. KwaZulu-Natal Department of Agriculture, Pietermaritzburg, South Africa.

CASTRO-ESAU KL, SANCHEZ-AZOFEIFA GA and CAELLI T (2004) Discrimination of lianas and trees with leaf level hyperspectral data. Remote Sens. Environ. 90 353-372.

EVERSON CS, MOODLEY M, GUSH MB, JARMAIN CJ, GOVENDER M and DYE PJ (2006) Can Effective Management of Riparian Zone Vegetation Significantly Reduce the Cost of Catchment Management and Enable Greater Productivity of Land Resources. WRC Report No. K5/1284. Water Research Commission, Pretoria, South Africa.

FOODY GM and MATHUR A (2006) The use of training sets containing mixed pixels for accurate hard image classification: Training on mixed spectral responses for classification by SVM. Remote Sens. Environ. 103 179-189.

GALVAO LS, FORMAGGIO AR and TISOT DA (2005) Discrimination of sugarcane varieties in South Eastern Brazil with EO-1 Hyperion data. Remote Sens. Environ. 94 523-534.

GOVENDER M, CHETTY K and BULCOCK H (2007) A review of hyperspectral remote sensing and its application in vegetation and water resource studies. Water $S A 33$ 145-151.

GREEN AA, BERMAN M, SWITZER P and CRAIG MD (1988) A transformation for ordering multispectral data in terms of image quality with implications for noise removal. IEEE Trans. Geosci. Remote Sens. 26 65-74.

ISMAIL R, MUTANGA O and AHMED F (2007) Discriminating Sirex noctilio attack in pine forest plantations in South Africa using high spectral resolution data. In: Kalacska M and Sanchez-Azofeifa A (eds.) Hyperspectral Remote Sensing of Tropical and Sub-Tropical Forests. Taylor and Francis: CRC Press, Routledge, USA. 350 pp.

KOCH M, INZANA J and EL BAZ F (2005) Applications of Hyperion hyperspectral and aster multispectral data in characterizing vegetation for water resource studies in arid lands. Paper No. 44-5. Proc. Geol. Remote Sens. Annual Meeting. 16-19 October 2005, Salt Lake City, USA

KRUCE F, LEFKOFF A, BOARDMAN J, HEIDEBRECHT K, SHAPIRO A, BARLOON P and GOETZ A (1993) The spectral image processing system (SIPS) interactive visualization and analysis of imaging spectrometer data. Remote Sens. Environ. 44 145-163.

LANDGREBE D (1999) On information extraction principles for hyperspectral data. Cybernetics 28 part c, 1, 1-7.

LEE JB, WOODYATT AS and BERMAN M (1990) Enhancement of high spectral resolution remote sensing data by a noise-adjusted principal components transform. IEEE Trans. Geosci. Remote Sens. 28 295-304.

LILLESAND TM and KIEFER RW (1999) Remote Sensing and Image Interpretation. John Wiley \& Sons, Inc. New Jersey, USA.

RESEARCH SYSTEMS INC. (2005) RSI Training Series: Spectral Analysis with ENVI. 4990 Pearl East Circle, Boulder, CO 80301, USA.106 pp.

RICHARDS JA and JIA X (1999) Remote Sensing Digital Image Analysis. Springer Verlag, Berlin, Germany, $363 \mathrm{pp.}$

SOUTH S, QI J and LUSCH DP (2004) Optimal classification methods for mapping agricultural tillage practices. Remote Sens. Environ. 91 90-97. 
THOMLINSON JR, BOLSTAD PV and COHEN WB (1999) Coordinating methodologies for scaling land-cover classifications from site-specific to global: steps toward validating global map products Remote Sens. Environ. 70 16-28.

UNDERWOOD E, USTIN S and DIPIETRO D (2003) Mapping nonnative plants using hyperspectral imagery. Remote Sens. Environ. 86 150-161.
VAIPHASA C, ONGSOMWANG S, VAIPHASA T and SKIDMORE AK (2005) Tropical mangrove species discrimination using hyperspectral data: a laboratory study. Estuarine, Coastal Shelf Sci. $\mathbf{6 5}$ 371-379.

YAMANO H, CHEN J and TAMURA M (2003) Hyperspectral identification of grassland vegetation in Xilinahot, Inner Mongolia, China. Int. J. Remote Sens. 24 3171-3178. 